\title{
Quantification Series of Procalcitonin Decides the Conceivable Bacterial Infection among Vital Organs
}

\author{
Chindhiha $S^{1}$, Fahima Sheerin $S M H^{1}$, Divya $S^{1}$, Sherafin Vincy ${ }^{1 \#,}$ \\ Chandrasekar $\mathbf{M}^{1 \#}$, Selvakumar $K^{2}$ \\ \#Asst. Prof, ${ }^{1}$ Department of Medical Laboratory Technology, Loyola College, Nungambakkam Chennai, India \\ ${ }^{2}$ Department of Clinical Biochemistry, Billroth Hospitals, Shenoy Nagar, Chennai, India
}

Corresponding Author: Selvakumar K

\begin{abstract}
Sepsis is the occurrence of infection in association with the systemic inflammatory response syndrome (SIRS). Bacterial sepsis is one of the major illnesses that shows severe symptoms which leads to organ dysfunction. Procalcitonin (PCT) the precursor of the hormone calcitonin shows a huge impact on the diagnosis of sepsis caused by the bacterial infection. Many studies have also insisted the importance of PCT as a biomarker for sepsis. As early diagnosis is the key factor to overcome the difficulties of the sepsis, PCT acts a prominent diagnostic tool to acquire the desired results. This study focused on the role of PCT in correlation with supporting parameters of the vital organs such as renal markers, liver enzymes and pancreatic enzymes to reduce the organ dysfunction and its complications.
\end{abstract}

Key Words: Sepsis, procalcitonin, renal markers, liver enzymes, pancreatic enzymes

\section{INTRODUCTION}

Procalcitonin as the name implies it is a prohormone of the calcitonin. It begins from the calcitonin I (CALC-1) gene on chromosome 11 . The parafollicular cells (Ccells) of thyroid and neuroendocrine cells of the lung and intestine produce procalcitonin. Procalcitonin (PCT) is a member of different class of molecules, called "hormokines," it means the hormones behave like cytokines during any inflammation and infection (1). These hormokines are produced directly by microbial toxins or indirectly by a humoral or cell mediated host response ${ }^{(2)}$. During the bacterial infection, the production of PCT by the CALC-1 gene is found to be increasing in multiple extra thyroid tissues throughout the body ${ }^{(3)}$. In the course of infection, the neuroendocrine cells in the lungs or intestine produce noticeable PCT in the plasma and not produced by C-cells of the thyroid ${ }^{(1)}$.

The infectious condition is termed as Sepsis. Sepsis is a resultant of bacteria, virus, fungi or parasites or it could be due to any possible infections throughout the body (4). The infection in organs such as lungs, abdomen, and the urinary tract are the most prevalent source of infection that develops into sepsis ${ }^{(5)}$. Sepsis causes a broad spectrum of illness that shows a wide range of signs and symptoms which may also lead to organ dysfunction in severe conditions and septic shock or even death in most severe cases ${ }^{(6)}$. The symptoms of sepsis include high heart rate, fever and shivering, confusion or disorientation, shortness of breath and extreme pain or discomfort ${ }^{(7)}$. One of the leading causes of mortality is due to the impact of sepsis and its complications in the health sector ${ }^{(8)}$.

During sepsis, the release of PCT increases rapidly and persists for a long time, their levels also correlate with severity of sepsis. The change in the PCT levels plays a vital role in the diagnosis of sepsis (9). The rapid release of PCT can be 
detectable within 2 to 4 hours and their level reaches the peak by 12 to 24 hours ${ }^{(5)}$. It takes approximately $1-1 \frac{1 / 2}{2}$ days to reduce into half the concentration of the circulating procalcitonin in the plasma ${ }^{(1)}$. There is a specific increase of the PCT in the inflammatory processes induced by bacteria in comparison with cytokines, which are not specific for particular types of inflammation (3)

Bacterial sepsis is defined as the symptomatic bacteremia, with or without organ dysfunction. Sepsis is the presence of infection in concurrence with the systemic inflammatory response syndrome (SIRS) (10). For the diagnosis of bacterial sepsis, blood culture is the gold standard method to confirm the causative agent and drug sensitivity. But this method takes time to provide diagnostic results ${ }^{(11)}$. Since early diagnosis is considered as an important factor to find the severity of sepsis, PCT is the successful biomarker that has shown a reliable result in the early diagnosis of sepsis ${ }^{(12)}$.

Sepsis associated with organ dysfunction is one of the most common conditions that increase the risk of mortality. The vital organs such as kidney, liver and pancreas undergo organ failure due to many reasons. In sepsis, the kidney is affected in two ways; one way is that the infection would have originated from the kidney in the other way the cascade of events from sepsis cause damage to kidney. Both results in low blood pressure and disseminated intravascular coagulation which leads to kidney failure ${ }^{(13)}$. The liver is damaged by the toxins released by the bacteria or inflammatory mediators. The liver injury happens in a progressive way starting from hepatocellular dysfunction and finally it leads to liver failure. Since liver plays a major role in the body, liver damage before or after the onset of sepsis has a huge impact on the severity of the patient ${ }^{(14)}$. In sepsis condition, the prevalence of pancreatic injury is not consistent. According to guidelines, the increase in pancreatic enzymes such as amylase and lipase should be three times more than their normal levels are considered as acute pancreatitis ${ }^{(15)}$.

\section{MATERIALS AND METHODS EXPERIMENTAL DESIGN}

The study was conducted at Billroth Hospitals, Shenoy Nagar, Chennai-600030, since the study is based on sepsis, most of the patients were from ICU and CT-ICU's. Both male and female were selected irrespectively of age and the samples received at laboratory for procalcitonin testing were considered for the study.

\section{BLOOD SAMPLE COLLECTION:}

Most of patients were admitted under the restricted area e.g., ICU, CCU and CT-ICU. So, it is hard to collect the sample at bed side. But the samples will be collected by the physicians and the ward nursing staff. The serum sample will be collected using the vacutainer and kept for 30 mins and then centrifuged for 15 mins at $3500 \mathrm{rpm}$. The separated serum was used for testing procalcitonin and other biochemical analysis.

The biochemical analysis was carried out in a fully automated laboratory. The instruments used were Beckman Coulter AU480 - Clinical Chemistry analyser, QDxInstacheck ${ }^{\mathrm{TM}} \mathrm{PCT}$, Agappe MISPA- $i 2$ and Centrifuge. The following biochemical tests was evaluated

- Procalcitonin by Sandwich Immunodetection Method

- Urea by Glutamate Dehydrogenase Method

- Creatinine by Jaffe's Method

- Aspartate transaminase and Alanine transaminase by UV Kinetic Method

- Amylase by Kinetic Colour Test Method

- Lipase by Photometric Method

- C-reactive protein by Nephelometry Method

\section{RESULTS}

Among the 113 patients, the procalcitonin levels were assessed to identify the severity of the infection. In this 
study the patients with procalcitonin level ranging from 2-10 and $>10$ are taken into considerations. From the total no. of patients, 59 patients fall into the category of the levels 2-10. The remaining 54 patients, falls into the category of the level $>10$ (Fig.1).

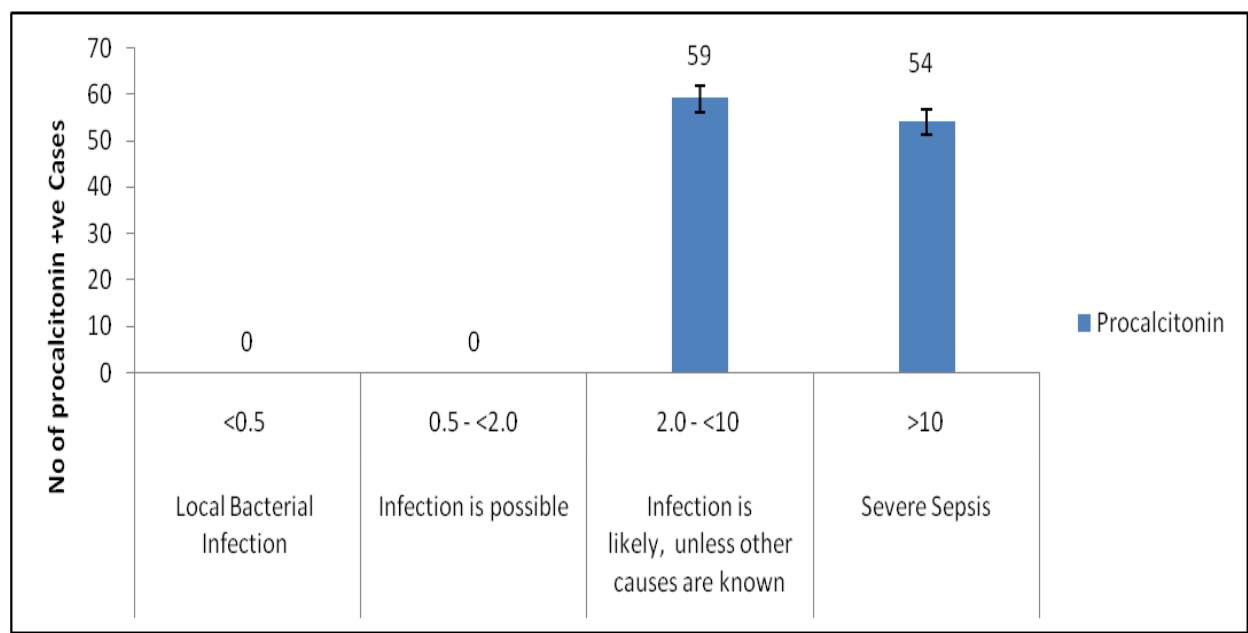

Fig.1. Assessment of patients with severe infection using procalcitonin

Each bar represents the total no of patients with severe infection according to their procalcitonin level. Statistically $5 \%$ of the total occurrence was considered as Standard Error (SE) for the statistical significance

The bar chart represents the number of patients with microbial growth in urine and aerobic blood culture. Among 106 patient's urine culture, microbial growth was observed in 30 patients alone, 3 patient's blood culture showed growth from a total of 97 patients (Fig.2).

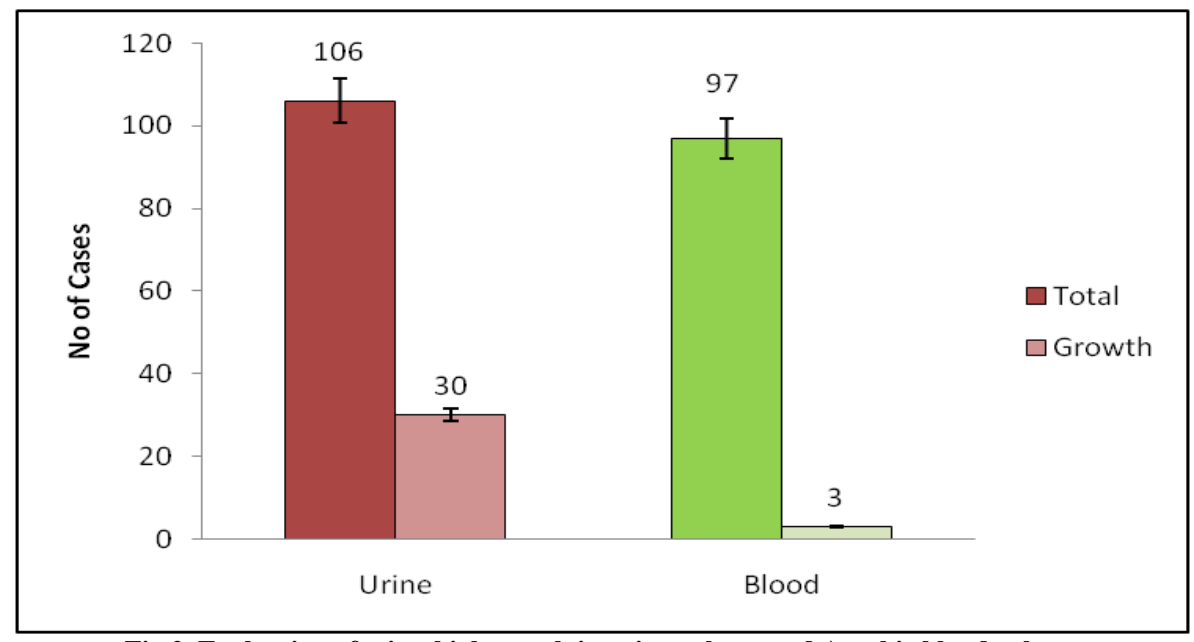

Fig.2. Evaluation of microbial growth in urine culture and Aerobic blood culture

Each bar represents the total no. of individuals Vs microbial growth in urine and blood culture. Statistically 5\% of the total occurrence was considered as Standard Error (SE) for the statistical significance

The procalcitonin positive patients were separated in two categories based on the severity of the infection $(2-10 \mathrm{ng} / \mathrm{mL}$, $>10 \mathrm{ng} / \mathrm{mL}$ ). Based on the severity the organ specific categorization like renal, liver, and pancreas was done to find the specific organ bacterial infection and multi- organ dysfunction. Patients who have procalcitonin positive alone are falls under the possible infection category (2$<10 \mathrm{ng} / \mathrm{ml}$ ). The results reveals that the patients who have the severe infection $(>10 \mathrm{ng} / \mathrm{ml})$ are mostly complicate with the other specific organ marker elevation (Fig.3). 
Chindhiha S et.al. Quantification series of procalcitonin decides the conceivable bacterial infection among vital organs.

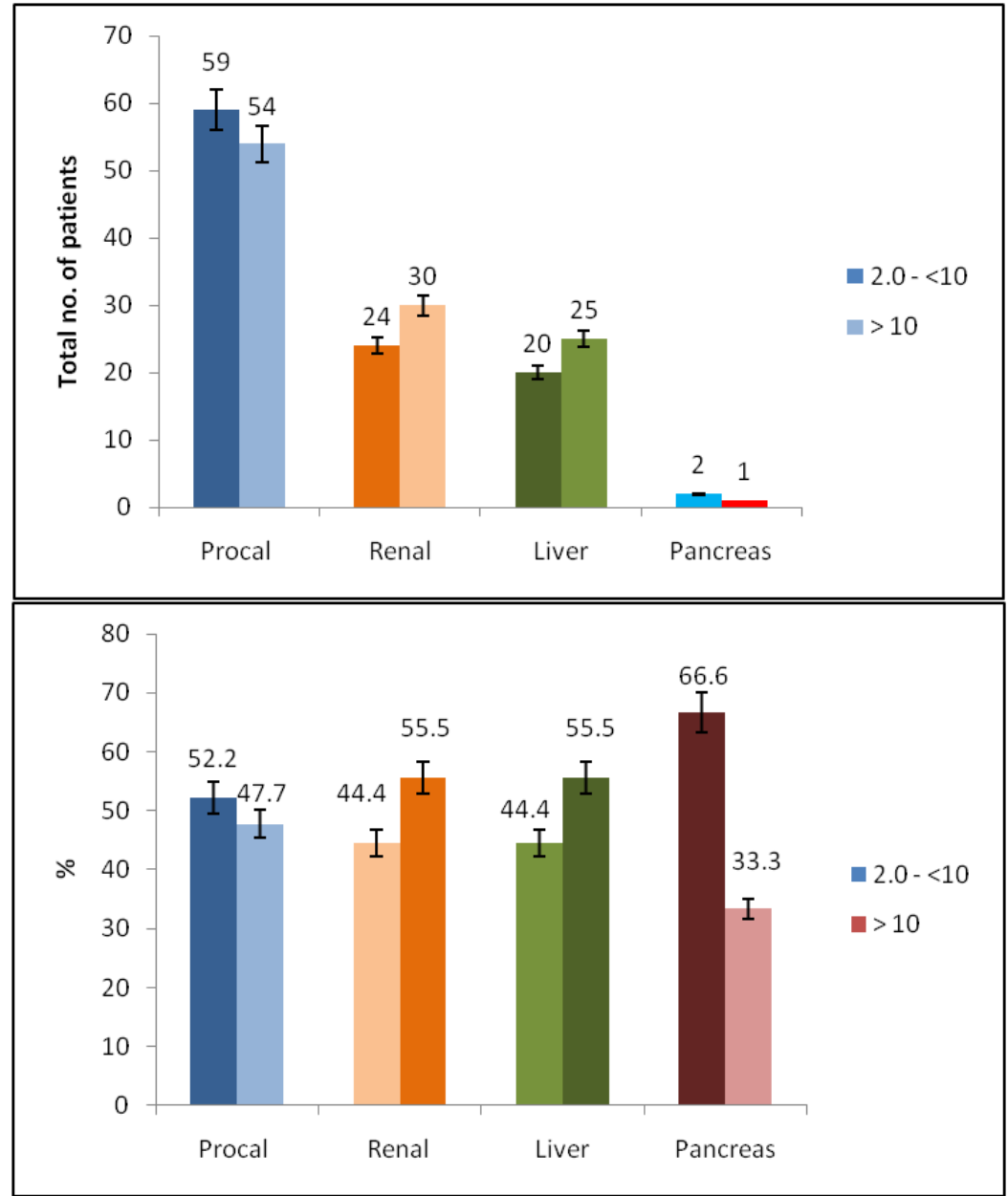

Fig.3. Evaluation of procalcitonin severity based on organ specific categorization

Each bar represents the total no. of procalcitonin positive patients in correspondence with renal markers, liver and pancreatic enzymes. Statistically $5 \%$ of the total occurrence was considered as Standard Error (SE) for the statistical significance

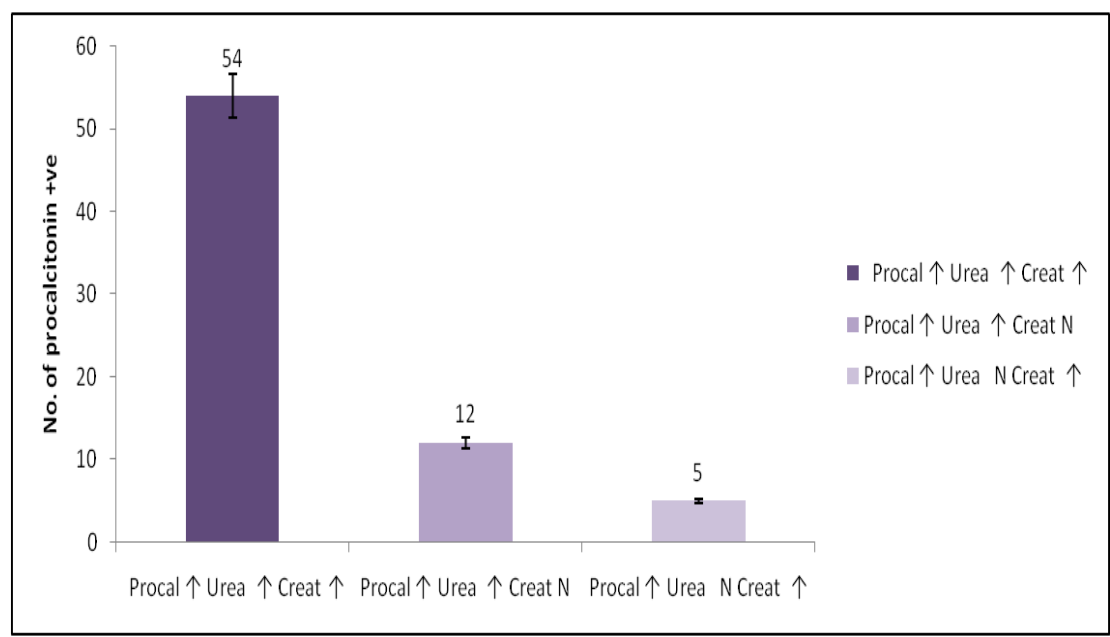

Fig.4. Estimation of serum urea and creatinine levels in patients with high procalcitonin

Each bar represents the no. of patients with infection in accordance with Urea and Creatinine levels. Statistically $5 \%$ of the total occurrence was considered as Standard Error (SE) for the statistical significance

For patients with procalcitonin positive, serum urea and creatinine levels were estimated. The differential proposition like Urea $\uparrow$ \&Creatinine $\uparrow$, Urea $\uparrow$ \&Creatinine Normal, Urea Normal
$\&$ Creatinine $\uparrow$ were checked. Among these category Urea $\uparrow \&$ Creatinine $\uparrow$ was found in many patients (Fig.4)

In this bar chart, the urine and blood culture growth were analyzed for patient 
with Urea $\uparrow \&$ Creatinine $\uparrow$ (Fig.4.) From the total of 54 patients with Urea $\uparrow$ and Creatinine $\uparrow$, urine culture of 35 patients showed no growth and the remaining 19 showed significant growth with different species of microorganisms. In the blood culture 52 patients showed no growth and 2 showed significant growths with similar bacterial identification (Fig.5).

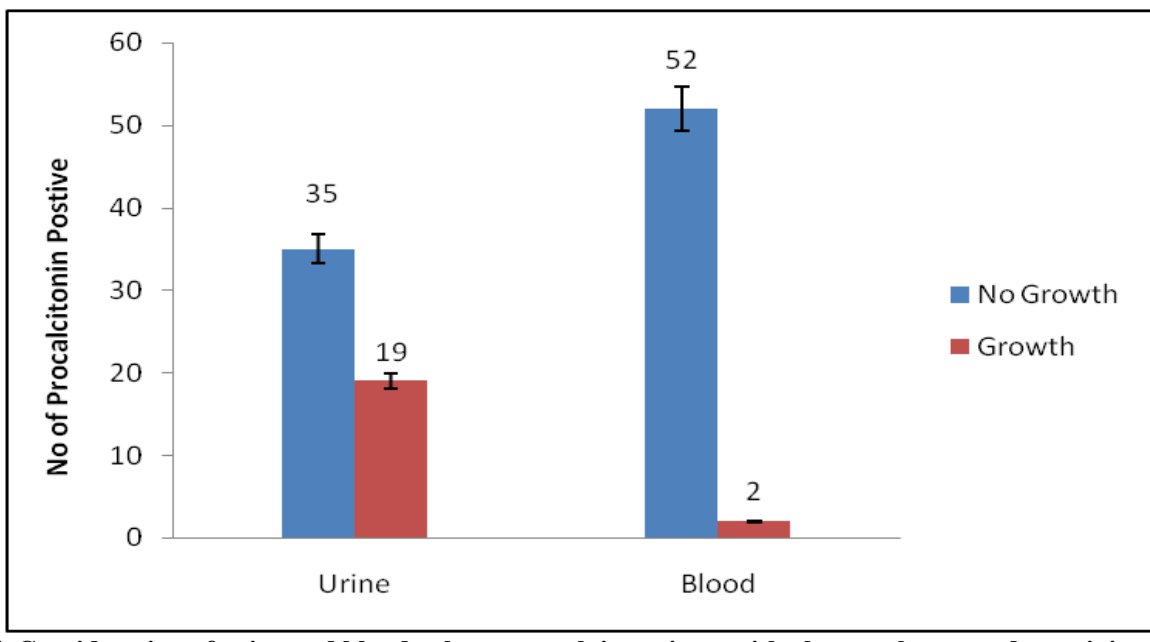

Fig.5. Consideration of urine and blood culture growth in patients with abnormal urea and creatinine levels Each bar represents the no. of procalcitonin positive patients along with high levels of urea and creatinine corresponding to their growth and No growth in urine and blood culture. Statistically 5\% of the total occurrence was considered as Standard Error (SE) for the statistical significance

The assessment of specific species growth for 19 patients from Fig.5 was identified. Most of the urine culture results were found to be Escherichia coli ${ }^{(10)}$. Other than Escherichia coli some of the microorganisms like Enterococcus species,

Staphylococcus aureus, Klebsiella pneumonia, Non albicans candida, Acinetobacter species were also observed. In the blood culture 3 positives cases were noted which showed growth of Escherichia coli (Fig.6).

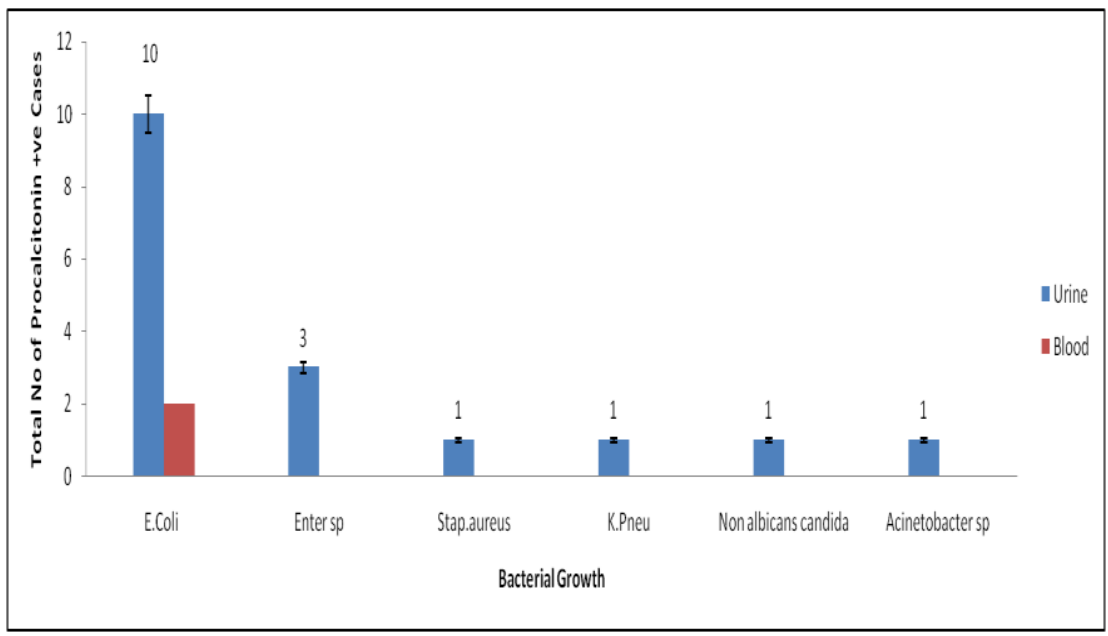

Fig.6. Assessment of patients with infection using the microbial urine culture

Each bar represents the no. of procalcitonin positive patients with the growth of specific microorganisms in urine culture. Statistically $5 \%$ of the total occurrence was considered as Standard Error (SE) for the statistical significance

For patients with procalcitonin positive serum AST and ALT were estimated. The differential proposition like AST $\uparrow \&$ ALT $\uparrow$, AST N \&ALT N, AST $\uparrow$ \&ALT N, AST N \&ALT $\uparrow$. From the above mentioned cases, the patients with AST $\uparrow$
ALT $\uparrow$ also falls under the category of Urea $\uparrow$ Creatinine $\uparrow$. This study reveals that there are few patients have both liver enzymes and the renal makers were high, which indicates the multi-organ bacterial infection (Fig.7). 

organs.

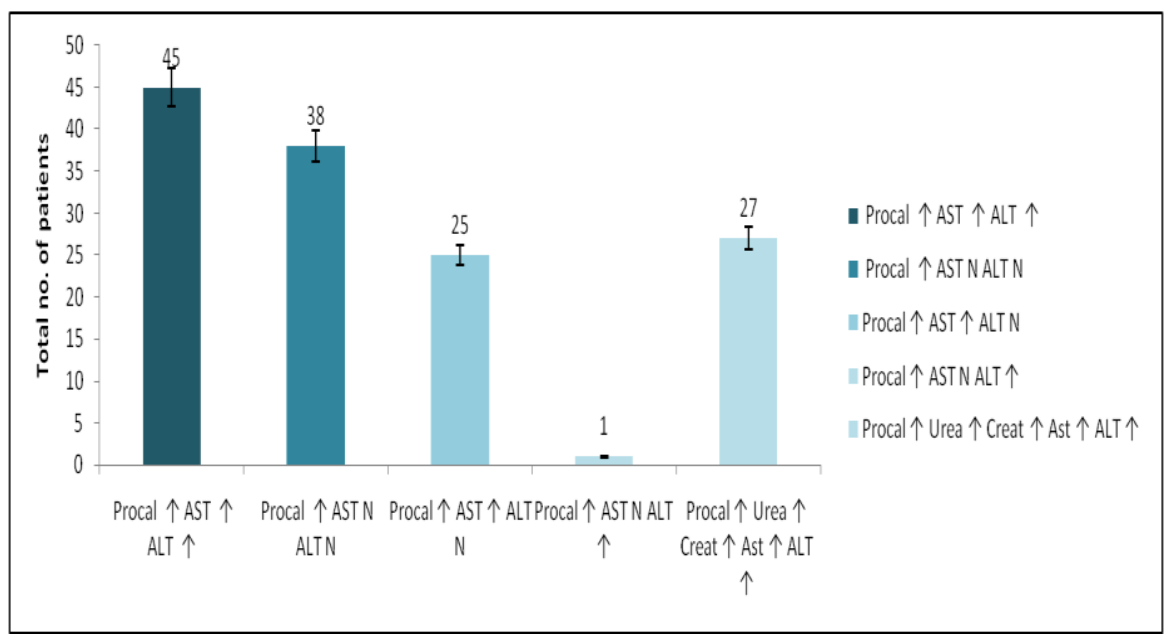

Fig.7. Estimation of Aspartate transaminase and Alanine transaminase levels in patients with high procalcitonin Each bar represents the no. of procalcitonin positive patients in accordance with Aspartate transaminase and Alanine transaminase levels. Statistically 5\% of the total occurrence was considered as Standard Error (SE) for the statistical significance

For the patients with procalcitonin patients had Amylase $\uparrow \&$ Lipase $\uparrow, 1$ positive, pancreatic enzymes such as patient with Amylase $\mathrm{N}$ Lipase $\uparrow$, the amylase and lipase were correlated. A total remaining 8 patients had normal amylase \& of 13 patients were analyzed, among them 3 lipase levels (Fig.8).

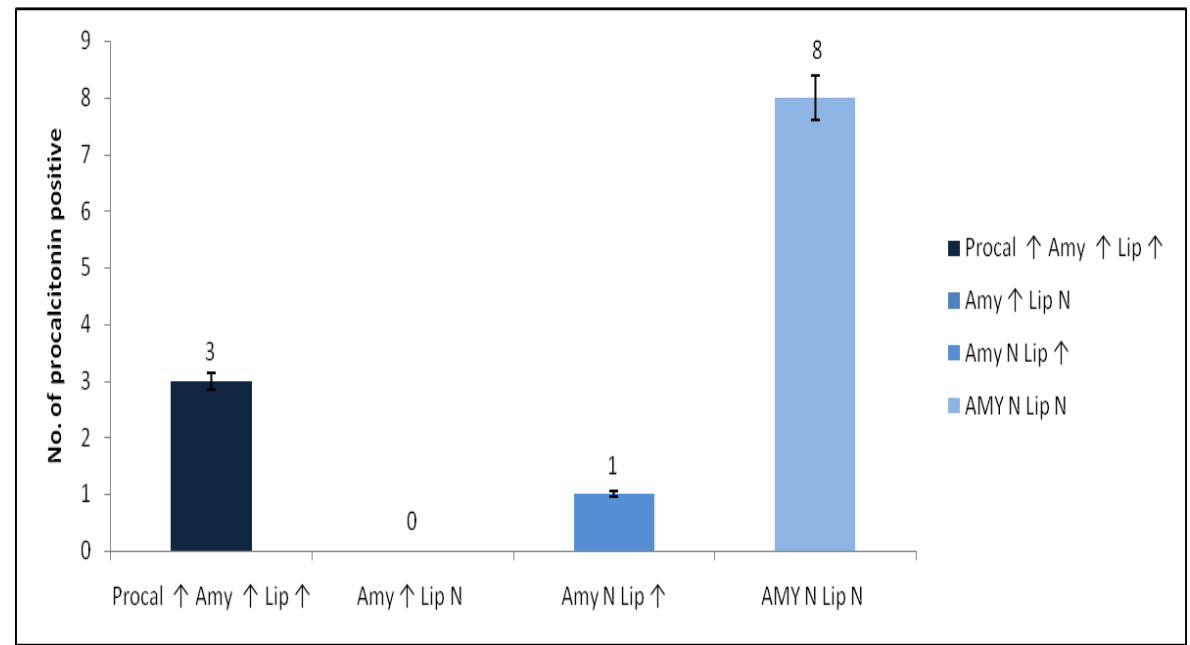

Fig.8. Correlation of amylase and lipase in patients with high procalcitonin levels

Each bar represents the no. procalcitonin positive patients in association with amylase and lipase levels. Statistically $5 \%$ of the total occurrence was considered as Standard Error (SE) for the statistical significance

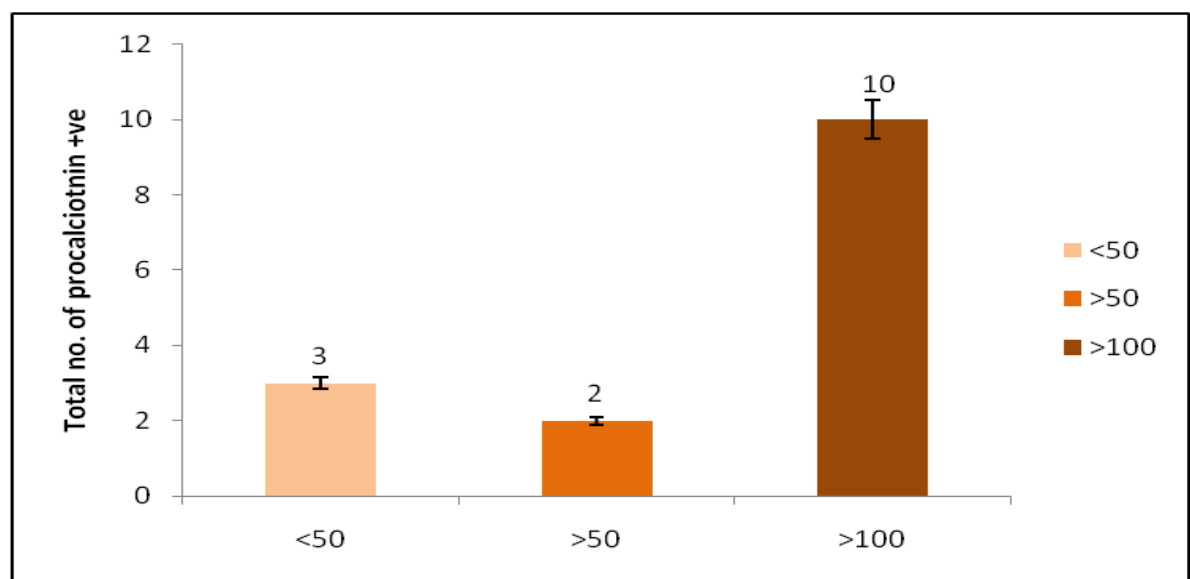

Fig.9. Estimation of immunological reaction using $\mathrm{C}$ - Reactive protein among procalcitonin positive patients 
Each bar represents the total no. of procalcitonin positive patients Vs C-Reactive protein. Statistically 5\% of the total occurrence was considered as Standard Error (SE) for the statistical significance

The immunological prognostic marker CRP was estimated for the procalcitonin positive patients. The result shows that above $66 \%$ of the cases are very high in the immunological marker which confirms the acute to chronic infection (Fig.9)

\section{DISCUSSION}

The studies have found that PCT shows a high diagnostic performance for the diagnosis of blood stream infections and bacteremia $^{(16)}$. A study shows that PCT cutoff could be able to differentiate Gramnegative from Gram-positive and fungal bloodstream infections. The PCT can be evaluated within 20 mins of time. For gram negative infection the PCT cut-off can be $\geq 10.8 \mathrm{ng} / \mathrm{mL}$ and for Enterobacteriaceae infection the PCT cut-off could be $\leq 3.1$ $\mathrm{ng} / \mathrm{mL}^{(17)}$.

Except for patients on Continuous ambulatory peritoneal dialysis (CAPD) all the other renal failure patients, PCT seems to be much more specific for bacterial infections than CRP ${ }^{(18)}$. Our study shows procalcitonin can be used to diagnose organ based infections by correlation with the supporting parameters. In the case of kidney, renal markers such as Urea and Creatinine can be correlated along with procalcitonin to find kidney infections. Similarly, PCT also helps us to identify the Urinary tract infections by identifying the exact microbial infection using culture and antibiotic susceptibility test. From our study $E$. coli has been found to be more prevalent from the results obtained. This could help to start the first line of drugs for primary infection, and this could also prevent the patients by administering the heavy antibiotics or steroids initially which ultimately precludes the patients to undergoing multi drug resistance.

In sepsis condition liver dysfunction causes a major risk factor for multiple organ dysfunction and sepsis-induced death. Attenuating liver injury and restoring liver function lowers morbidity and mortality rates in patients with sepsis ${ }^{(19)}$. Due to regenerating capacity and drug intoxication by the liver, there is a high chance of elevation in AST and ALT. Early diagnosis of sepsis and its complications as well as executing medicinal support reduce the chance of severe organ complications, to shorten the hospitalization time and improve patients' quality of life ${ }^{(20)}$. In this study we evaluated liver enzymes such as aspartate transaminase (AST) and alanine transaminase (ALT) along with procalcitonin positive showed. The elevation of liver enzymes may be due to several bacterial infection of the liver or may be co-infection of some of the primary microbial infection.

For an early diagnosis of acute pancreatitis, the correlation of PCT value with total calcium concentration, lactic dehydrogenase activity, and glucose enable a basis for the preparation of clinical tests (21). This study also proves that in several bacterial infections there is an elevation of pancreatic enzymes such as amylase and lipase. Since the occurrence of the pancreatitis and PCT high case is low in this study we are not able to correlate with the specific root cause of the elevation. It can be supported with the serum levels of LDH, Calcium and Glucose.

CRP will provide the less information of the type of microorganism grown, and the type of bacteria present ${ }^{(18)}$. PCT is a more accurate diagnostic parameter for sepsis and a better predictor of mortality ${ }^{(22)}$. So PCT will be the preeminent biomarker to diagnose any microbial infection in a rapid and precise manner.

\section{CONCLUSION}

Procalcitonin played a significant role in the diagnosis of bacterial infection in single organ specific and multi-organ pattern. While compare with CRP it provides the rapid and precise results as immunological inflammatory reaction. Based on the range of PCT we can 
categorize the organism of bacteria which CRP cannot do. Using PCT as a primary diagnostic biomarker it could prevent multiple organ dysfunction and multi drug resistance cases at the earliest.

\section{Acknowledgement: None}

\section{Conflict of Interest: None}

\section{Source of Funding: None}

\section{Ethical Approval: Approved}

\section{REFERENCES}

1. Meisner M. (2002). Pathobiochemistry and clinical use of procalcitonin. Clin Chim Acta. 323(1-2):17-29.

2. Müller B, Becker KL. (2001). Procalcitonin: how a hormone became a marker and mediator of sepsis. Swiss Med Wkly. 131(41-42):595-602.

3. Maruna P, Nedelníková K, Gürlich R. (2000). Physiology and genetics of procalcitonin. Physiol Res.49Suppl 1:S5761.

4. Zarakolu P, Akova M. (2005). Antimicrobial treatment in sepsis. YoğunBakımDergisi; 5: 103-8.

5. Munford Robert S, Suffredini Anthony F. (2014). Sepsis, Severe Sepsis and Septic Shoc. In: Bennett John E, Dolin Raphael, Blaser Martin J, Mandell, Douglas, and Bennett's Principles and Practice of Infectious Diseases. ( $8^{\text {th }}$ edn), Philadelphia, Elsevier Health Sciences, 914-934.

6. Lever A, Mackenzie I. (2007). Sepsis: definition, epidemiology, and diagnosis. BMJ. 335(7625):879-83.

7. Centre for disease control \& prevention, 2010

8. Vincent JL, Sakr Y, Sprung CL, Ranieri VM, Reinhart K, Gerlach H, Moreno R, Carlet J, Le Gall JR, Payen D. (2006). Sepsis Occurrence in Acutely Ill Patients Investigators. Sepsis in European intensive care units: results of the SOAP study. Crit Care Med. 34(2):344-53.

9. Tavares E, Miñano FJ. (2010). Immunoneutralization of the aminoprocalcitonin peptide of procalcitonin protects rats from lethal endotoxaemia: neuroendocrine and systemic studies. ClinSci (Lond). 119(12):519-34.

10. Levy MM, Fink MP, Marshall JC, Abraham E, Angus D, Cook D, Cohen J, Opal SM, Vincent JL, Ramsay G; (2003). International Sepsis Definitions Conference. 2001 SCCM/ESICM/ACCP/ATS/SIS

International Sepsis Definitions Conference. Intensive Care Med. 29(4):530-8.

11. Angus DC, Linde-Zwirble WT, Lidicker J, Clermont G, Carcillo J, Pinsky MR. (2001). Epidemiology of severe sepsis in the United States: analysis of incidence, outcome, and associated costs of care. Crit Care Med. 29(7):1303-10.

12. Vijayan AL, Vanimaya, Ravindran S, Saikant R, Lakshmi S, Kartik R, G M. (2017). Procalcitonin: a promising diagnostic marker for sepsis and antibiotic therapy. J Intensive Care.5:51.

13. Sepsis Alliance, Kidney Failure, (2019).

14. Jarrar D WP, Chaudry IH. (2001). Hepatocellular dysfunction-basic considerations. In: Holzheimer RG MJ,editor. Surgical treatment: evidencebased and problem-oriented.Munich: Zuckschwerdt.

15. Pezzilli R, Barassi A, Imbrogno A, Fabbri D, Pigna A, Morselli-Labate AM, Corinaldesi R, Melzi d'Eril G (2011). Is the pancreas affected in patients with septic shock?--a prospective study. Hepatobiliary Pancreat Dis Int; 10:191-195.

16. Van der Meer W, Pickkers P, Scott CS, van der Hoeven JG, Gunnewiek JK. (2007). Hematological indices, inflammatory markers and neutrophil CD64 expression: comparative trends during experimental human endotoxemia. J Endotoxin Res. 13(2):94-100.

17. Leli C, Ferranti M, Moretti A, Al Dhahab ZS, Cenci E, Mencacci A. (2015). Procalcitonin levels in gram-positive, gram-negative, and fungal bloodstream infections. Dis Markers; 701480.

18. Steinbach G, Bölke E, Grünert A, Störck M, Orth K. (2004). Procalcitonin in patients with acute and chronic renal 
insufficiency. Wien Klin Wochenschr; 116(24):849-853.

19. Yan, J., Li, S., \& Li, S. (2014). The role of the liver in sepsis. International reviews of immunology, 33(6), 498-510.

20. Woźnica EA, Inglot M, Woźnica RK, Łysenko L. (2018). Liver dysfunction in sepsis. Adv Clin Exp Med. 27(4):547551.

21. Gurda-Duda A, Kuśnierz-Cabala B, Nowak W, Naskalski JW, Kulig J. (2008). Assessment of the prognostic value of certain acute-phase proteins and procalcitonin in the prognosis of acute pancreatitis. Pancreas. 37(4):449-53.

22. Shiferaw B, Bekele E, Kumar K, Boutin A, Frieri M. (2016). The Role of Procalcitonin as a Biomarker in Sepsis. J Infect Dis Epidemiol.

How to cite this article: Chindhiha S, Fahima Sheerin SMH, Divya S et.al. Quantification series of procalcitonin decides the conceivable bacterial infection among vital organs. International Journal of Research and Review. 2021; 8(3): 475-483. DOI: https:// doi.org/10.52403/ijrr.20210457 